\title{
ВЛИЯНИЕ ВИДОВОГО СОСТАВА ТРАВ НА СОДЕРЖАНИЕ МАКРОЭЛЕМЕНТОВ И КОРМОВЫХ ЕДИНИЦ В ПАСТБИЩНЫХ КОРМАХ
}

L.P. Baykalova, I.A. Gorbachev

\section{THE INFLUENCE OF SPECIES COMPOSITION OF GRASSES ON THE CONTENT OF MACROELEMENTS AND FODDER UNITS IN PASTURE FEED}

Байкалова Л.П. - д-р с.-х. наук, профр. каф. растениеводства, селекции и семеноводства Красноярского государственного аграрного университета, г. Красноярск.

E-mail: kos.69@mail.ru

Горбачев И.А. - асп. каф. растениеводства, селекции и семеноводства Красноярского государственного аграрного университета, г. Красноярск. E-mail: gorigal005@mail.ru

Цель исследования - изучение влияния видового состава на содержание макроэлементов и кормовых единиц в пастбищных кормах из многолетних злаково-бобовых трав. Объектами исследования послужили многолетние злаковые и бобовые травы и их смеси в разных процентных соотношениях от нормы высева, рекомендуемых для лесостепной зоны. Показатель гидротермического коэфффициента 2014 г. соответствовал достаточному увлажнению, 2016 г. - недостаточному, в 2015 г. умеренному. Содержание кальция зависело от цикла стравливания, погодных условий лет исследования, вида трав и увеличивалось от первого иикла стравливания к третьему. Пастбищные травосмеси превосходили контроль овсяницу красную по содержанию кальция на 0,85-2,29\%. Содержание фоосфрора и магния в сухом веществе пастбищных кормов зависело от погодных условий лет исследования и иикла стравливания. Содержание фоосфора снижалось от первого цикла стравливания к третьему: 0,86; 0,79 и 0,49\% соответственно. Содержание магния увеличивалось om первого цикла стравливания к третьему: om 0,26-0,71 \% в первом, 0,33-0,54 во втором до 0,47-0,67 \% в третьем иикле стравливания. В зависимости от иикла стравливания достоверных различий по содержанию кормо-
Baykalova L.P. - Dr. Agr. Sci., Prof., Chair of Plant Growing, Selection and Seed Farming, Krasnoyarsk State Agrarian University, Krasnoyarsk.

E-mail:kos.69@mail.ru

Gorbachev I.A. - Post-Graduate Student, Chair of Plant Growing, Selection and Seed Farming, Krasnoyarsk State Agrarian University, Krasnoyarsk.

E-mail: gorigal005@mail.ru

вых единиц нет. На содержание кормовых единиц оказывал влияние видовой состав трав и травосмесей в первом и третьем циклах стравливания. На сбор кормовых единиц многолетних пастбищных трав большее влияние оказывал фрактор «культура, смесь» - $67 \%$. Сбор кормовых единиц зависел от содержания кормовых единиц в сухом веществе пастбищных кормов, выхода с единицы площади сухого вещества, погодных условий и цикла стравливания. Исследуемые травосмеси многократно превосходили контроль по сбору кормовых единиц: в первом цикле стравливания - в 3,15,3 раза, во втором иикле - в 3,4-4,9 раза, в третьем цикле стравливания - в 3,8-5,8 раз.

Ключевые слова: содержание кальщия, фоссфора, магния, кормовые единицы, цикл стравливания, пастбищные корма.

The research objective was studying the influence of specific structure on the content of macroelements and feed units in pasture sterns from perennial cereals and legumes. As the objects of the research perennial cereals and legumes and their mixtures served in different percentage ratios from the norm of seeding recommended for a forest-steppe zone. The indicator of hydrothermal coefficient of 2014 corresponded to sufficient moistening, 2016 - insufficient, in 2015 - moderate. The 
content of calcium depended on the cycle of grazing, weather conditions of the years of the research, grasses species and increased from the first cycle of grazing to the third. Pasture grass mixture surpassed control, i.e. Festuca rubra in the content of calcium for $0.85-2.29 \%$. The content of phosphorus and magnesium in solid pasture feed depended on weather conditions of the years of the research and grazing cycle. The content of phosphorus decreased from the first cycle of grazing to the third: 0.86; 0.79 and $0.49 \%$, respectively. The content of magnesium increased from the first cycle of grazing to the third: from $0.26-0.71 \%$ in the first, $0.33-0.54$ in the second to $0.47-0.67 \%$ in the third cycle of grazing. Depending on the cycle of grazing of reliable distinctions according to the maintenance of fodder units was not present. Specific structure of grasses and grass mixture in the first and third cycles of grazing had the impact on the content of fodder units. The factor "culture, mix" $67 \%$ had a greater influence on feed units of perennial pasture grasses composition. The content of feed units depended on the maintenance of feed units in solid pasture forages, an exit from unit of area of solid, weather conditions and a cycle of grazing. Studied grass mixture repeatedly surpassed control in fodder units' composition: in the first cycle of grazing by 3.1-5.3 times, in the second cycle - by 3.4-4.9 times, in the third cycle of grazing - by 3.8-5.8 times.

Keywords: calcium content, phosphorus, magnesium, feed units, grazing cycle, pasture feed.

Введение. Эфффективность производства животноводческой продукции напрямую зависит от качества кормов, содержащих не только органические вещества, но и макроэлементы, важнейшими среди которых являются кальций, фоссрор и магний. Корма должны быть полноценными и дешевыми, а их производство должно опережать темпы равития животноводства $[2,5,9]$. В Красноярском крае за последние 20 лет доля пастбищной травы в летнем рационе крупного и мелкого рогатого скота снизилась вдвое. В связи С этим увеличилось производство кормов на пашне, что приводит к удорожанию их производства [3]. Оценка эфффективности пастбищного содержания дойных коров показывает, что удельные затраты на пастбищный корм в 2 раза меньше, чем при стойловом типе кормления. Расход горючего снижается почти в 7 раз, затраты труда механизаторов - в 2 раза. В пастбищный период качество молока улучшается по содержанию белка с 3,05 до 3,26 \%; по биологической полноценности жира - на 58 \%; витамина $F$ (аналога Омега-3) - в 4,3 раза; каротина и витамина $\mathrm{E}$ - почти в 2 раза; витамина A - на $73 \%$ [11].

Совершенствование состава сеяных пастбищных травостоев путем подбора адаптированных видов луговых трав является важнейшим направлением интенсификации лугового кормопроизводства, обеспечивающим экономию антропогенных затрат [10]. А. Ваузен приводит яркий пример из практики Англии, показывающий высокую результативность использования смешанных посевов [4]. При пастьбе овец на чистых посевах райграса многолетнего привес доходил до 292 кг из расчета на 1 га, ежи сборной - до 207 кг. На травостоях этих же трав в смеси с белым клевером привес был больше в первом случае на $19 \%$, во втором - на $50 \%$.

Цель исследования: изучение влияния видового состава на содержание макроэлементов и кормовых единиц в пастбищных кормах из многолетних злаково-бобовых трав.

Задачи исследования: 1) оценить пастбищные травосмеси по содержанию кальция, фосфора и магния в первом, втором и третьем циклах стравливания; 2) установить содержание кормовых единиц в сухом веществе пастбищных трав и травосмесей; 3) определить сбор кормовых единиц многолетних злаково-бобовых трав пастбищного назначения.

Методика исследования. Исследование проводилось в УНПК «Борский» Красноярского ГАУ, расположенного в лесостепной зоне Красноярского края, в 2014-2016 гг. на опытном поле кафедры растениеводства. Закладка опыта по долгосрочным пастбищам проводилась 12 мая 2011 г. Площадь каждого варианта опыта $700 \mathrm{M}^{2}$, способ посева - рядовой, сеялкой ССФК-7. Определялась урожайность угодий в трех циклах стравливания в фазу ветвления начала бутонизации: во второй декаде июня, во второй декаде июля и в третьей декаде августа первой декаде сентября.

Объектами исследования послужили многолетние злаковые и бобовые травы и их смеси пасбищного назначения в разных про- 
центных соотношениях от нормы высева, рекомендуемых для лесостепной зоны. Первый вариант - одновидовой посев овсяницы красной, используемый в качестве контроля; второй вариант - одновидовой посев овсяницы луговой; третий - тимофреевки луговой, четвертый - травосмесь кострец безостый $35 \%+$ овсяница луговая $70 \%$ + овсяница красная $50 \%$ + люцерна гибридная $45 \%$; пятый - травосмесь кострец безостый $35 \%$ + тимофреевка луговая $70 \%$ + овсяница красная $50 \%$ + люцерна гибридная $45 \%$; шестой - травосмесь кострец безостый 35 $\%$ + тимофееевка луговая $70 \%+$ овсяница красная $50 \%$ + галега восточная $25 \%$ + клевер красный $25 \%$ (табл. 1). Закладка опытов и наблюдения проводились согласно методике ВНИИ кормов им. В.Р. Вильямса [8]. Статистическая обработка результатов проведена по методикам Б.А. Доспехова [6], а также с использованием пакета статистических программ SNEDECOR в изложении О.Д. Сорокина [12].

Характеристика погодных условий была сделана по данным Архива погоды в Сухобузимском районе [1]. Средняя температура воздуха за период с мая по сентябрь по многолетним данным составила: май $-8,9{ }^{\circ} \mathrm{C}$; июнь - 17,5; июль - 20,0; август - 16,7; сентябрь $-8,7^{\circ} \mathrm{C}$. Однако 2014 г. характеризовался чуть меньшими температурами воздуха за период с мая по сентябрь, следовательно, лето было прохладным; 2015 г. наоборот был жарким, так как по всем месяцам прослеживалось увеличение температуры воздуха; 2016 г. был на уровне многолетних данных (рис. 1).

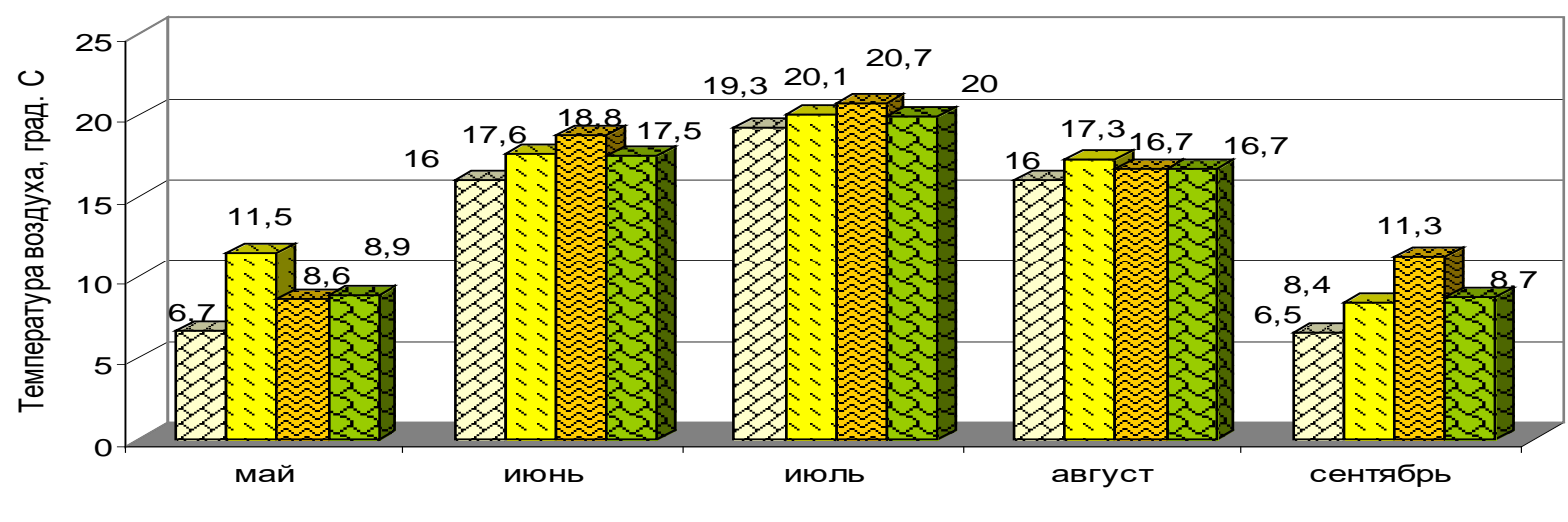

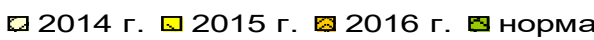

\section{Puc. 1. Средняя температура воздуха вегетационного периода Сухобузимского района в период исследований, ${ }^{\circ} \mathrm{C}$}

Сумма за вегетацию по многолетним данным составляла $1960{ }^{\circ} \mathrm{C}$, в 2014 г. эта сумма была чуть больше $1977{ }^{\circ} \mathrm{C}$, что характеризовалось жаркой погодой. В 2014, 2015 гг. сумма осадков за вегетацию превышала многолетние данные, что свидетельствовало о жаркой, но дождливой погоде. Распределение температур и осадков по месяцам было крайне неравномерным. Среднегодовое количество осадков за период май - сентябрь составляло 258 мм; за этот же период, в годы проведения исследования, выпало от 202 мм в 2016 г. до 301 мм осадков в 2014 г. ГТК в 2014 г. соответствовал достаточ- ному увлажнению, в 2015 г. - умеренному, а в 2016 г. - засушливым условиям.

Результаты исследования и их обсуждение. Установлено, что содержание кальция изменялось в зависимости от цикла стравливания, погодных условий лет исследования и вида трав. Содержание кальция увеличивалось от первого цикла стравливания к третьему. В первом и втором циклах стравливания максимальным оно было в 2014 г. В первом цикле стравливания в среднем в 2014 г. 1,24 \%, тогда как в 2015 и 2016 гг. - 1,23 и 0,89 \% соответственно (рис. 2). 


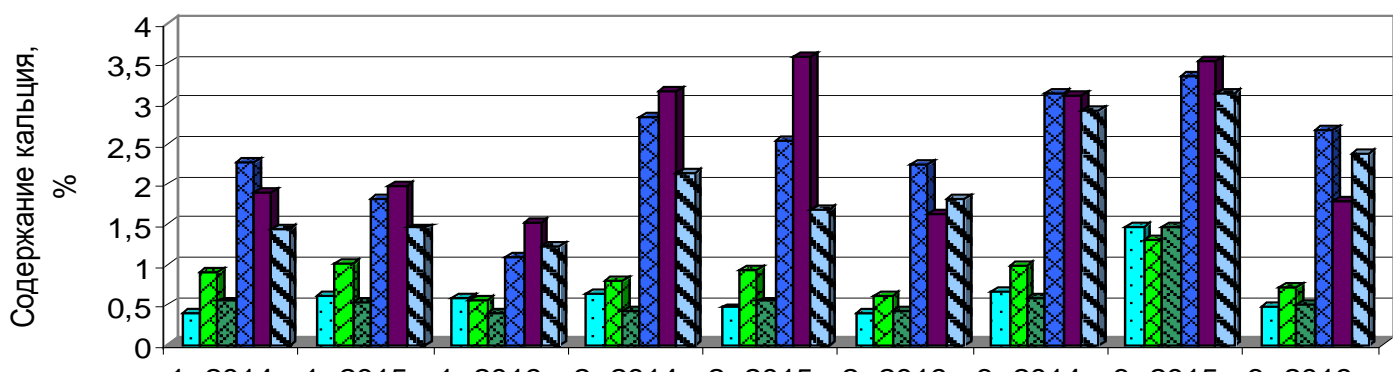

1: 2014 г.1: 2015 г. 1: 2016 r.2: 2014 г.2: 2015 г.2: 2016 г.3: 2014 г. 3: 2015 г.3: 2016 г.

๑ Овсяница красная, контроль

Тимофеевка луговая;

口 Кострец + тимофеевка + ов сяница красная + люцерна;
С Овсяница луговая;

■ Кострец+ов сяница луговая + ов сяница красная + люцерна

Кострец + тимфеев ка + ов сяница красная + галега + клевер

Puc. 2. Динамика содержания кальщия в сухом веществе многолетних трав пастбищного назначения, \%:

1: 2014 2., 1: 2015 е., 1:2016 2. - первый цикл стравливания;

2: 2014 г., 2: 2015 2., 2:2016 2. - второй цикл стравливания;

3: 2014 2., 3: 2015 е., 3: 2016 г. - третий цикл стравливания

Во втором цикле стравливания в 2014 г. содержание кальция в сухом веществе составляло $1,66 \%$, в 2015 и 2016 гг. - 1,62 и 1,18\% соответственно. В третьем цикле стравливания максимальное содержание кальция отмечено в 2015 г. Выявлено значительное преимущество смесей перед контролем и одновидовыми посевами многолетних трав по содержанию кальция во все годы исследования. В первом цикле стравливания максимальное содержание кальция было в 2014 г. у травосмеси кострец безостый $35 \%+$ овсяница луговая $70 \%+$ овсяница красная $50 \%$ + люцерна гибридная $45 \%$ - 2,28 $\%$; во втором и третьем циклах стравливания выделилась по содержанию кальция травосмесь кострец безостый $35 \%$ + тимофреевка луговая $70 \%$ + овсяница красная $50 \%$ + люцерна гибридная 45 \% в 2015 г. - 3,58 и 3,53 \% соответственно (см. рис. 2).

Выявлено значительное преимущество исследуемых пастбищных травосмесей по содержанию кальция перед контролем овсяницей красной во всех циклах стравливания. Травосмеси превосходили злаковый контроль по содержанию кальция в 3,1-3,3 раза в зависисмости от цикла стравливания. Содержание кальция в одновидовых посевах находилось на уровне контроля (табл. 1).

\section{Содержание макроэлементов в сухом веществе} многолетних пастбищных трав, 2014-2016 гг., \%

\begin{tabular}{|l|c|c|c|c|c|c|c|c|c|}
\hline \multirow{2}{*}{ Культура, смесь } & \multicolumn{3}{|c|}{ Са (кальций) } & \multicolumn{3}{c|}{$\mathrm{P}$ (фоссфор) } & \multicolumn{3}{c|}{$\mathrm{Mg}$ (магний) } \\
\cline { 2 - 12 } & $1^{*}$ & 2 & 3 & 1 & 2 & 3 & 1 & 2 & 3 \\
\hline 1 & 2 & 3 & 4 & 5 & 6 & 7 & 8 & 9 & 10 \\
\hline 1. Овсяница красная & 0,52 & 0,50 & 0,87 & 0,83 & 0,69 & 0,54 & 0,31 & 0,33 & 0,47 \\
\hline 2. Овсяница луговая & 0,82 & 0,78 & 1,00 & 0,88 & 0,64 & 0,46 & 0,30 & 0,41 & 0,67 \\
\hline 3. Тимофеевка луговая & 0,48 & 0,45 & 0,85 & 0,88 & 0,80 & 0,47 & 0,26 & 0,37 & 0,39 \\
\hline $\begin{array}{l}\text { 4. Кострец + овсяница луговая } \\
\text { +овсяница красная + } \\
\text { люцерна гибридная }\end{array}$ & 1,72 & 2,53 & 3,04 & 0,87 & 0,85 & 0,53 & 0,41 & 0,54 & 0,61 \\
\hline $\begin{array}{l}\text { 5. Кострец + тимофеевка + } \\
\text { овсяница красная +люцерна }\end{array}$ & 1,79 & 2,79 & 2,80 & 0,87 & 0,76 & 0,48 & 0,43 & 0,42 & 0,61 \\
\hline
\end{tabular}


Окончание табл. 1

\begin{tabular}{|l|c|c|c|c|c|c|c|c|c|}
\hline \multicolumn{1}{|c|}{1} & 2 & 3 & 4 & 5 & 6 & 7 & 8 & 9 & 10 \\
\hline $\begin{array}{l}\text { 6. Кострец + тимофеевка + } \\
\text { овсяница красная + галега + } \\
\text { клевер красный }\end{array}$ & 1,37 & 1,88 & 2,80 & 0,85 & 0,67 & 0,46 & 0,71 & 0,52 & 0,64 \\
\hline НСР $_{05 \text { Асмесь }}$ & 0,43 & 0,73 & 0,50 & 0,16 & 0,21 & 0,16 & 0,41 & 0,28 & 0,26 \\
\hline НСР $_{\text {05 в год }}$ & 0,30 & 0,52 & 0,35 & 0,12 & 0,15 & 0,12 & 0,29 & 0,20 & 0,19 \\
\hline
\end{tabular}

* Примечание: 1; 2; 3 - цикл стравливания.

Содержание фоосфора в сухом веществе многолетних трав и травосмесей пастбищного назначения снижалось от первого цикла стравливания к третьему: в первом цикле стравливания оно составляло 0,86 \%; во втором - 0,79; в третьем - 0,49 \%. Достоверных различий в среднем за трехлетний период между контролем и вариантами опыта по содержанию фоссрора не было (см. табл. 1). Однако по годам содержание фросфора существенно различалось. В первом цикле стравливания в 2014 г. в среднем в сухом веществе пастбищных кормов фоссфора содержалось 1,17 \%; в 2015 г. - 0,98; в 2016 г. $0,44 \%$. Во втором цикле стравливания - 0,83; 0,89 и 0,49\%, в третьем цикле стравливания 0,60; 0,38 и 0,50 \% соответственно.

Содержание магния в сухом веществе многолетних пастбищных трав увеличивалось от первого цикла стравливания к третьему, за исключением травосмеси кострец безостый $35 \%$ + тимофреевка луговая $70 \%$ + овсяница красная $50 \%$ + галега восточная $25 \%$ + клевер красный $25 \%$, у которой максимальное содержание магния отмечено в первом цикле стравливания. В среднем по вариантам опыта в первом цикле стравливания содержание магния составляло 0,40 \%; во втором - 0,43; в третьем - 0,57 \%. Достоверных различий пастбищных трав и травосмесей в сравнении с контролем овсяницей красной не было ни в одном цикле стравливания (см. табл. 1).

В первом цикле стравливания за годы исследования пастбищные травы и травосмеси за исключением третьей (кострец безостый + тимофреевка + овсяница красная + галега + кле- вер) не различались по содержанию магния в сухом веществе. Однако во втором и третьем циклах стравливания в зависимости от года выявлены существенные различия. Во втором цикле стравливания среднее по опыту содержание магния составило в 2014 г. 0,48 \%; в 2015 г. 0,33; в 2016 г. - 0,49\%. В третьем цикле стравливания в 2014 г. магния содержалось 0,66 \%; в 2015 г. - 0,44; в 2016 г. - 0,61\%.

Лучшим показателем рационального кормления является кормовая единица. Насчитывается 60 компонентов питания, требующих сбалансированности, основными среди которых являются кормовые единицы [7]. По содержанию кормовых единиц в сухом веществе пастбищных кормов в зависимости от цикла стравливания достоверных различий не выявлено. В первом цикле стравливания большее содержание кормовых единиц в сравнении с контролем было у овсяницы луговой, травосмесей кострец безостый $35 \%$ + овсяница луговая $70 \%$ + овсяница красная $50 \%$ + люцерна гибридная $45 \%$ и кострец безостый $35 \%+$ тимофеевка луговая $70 \%+$ овсяница красная $50 \%$ + люцерна гибридная $45 \%$. Овсяница луговая превосходила контроль овсяницу красную на 0,12 корм. ед./кг, варианты 4, 5 - на 0,16 корм. ед./кг. В третьем цикле стравливания на 0,17 корм. ед./кг превосходила контроль по содержанию кормовых единиц травосмесь кострец безостый $35 \%$ + тимофреевка луговая $70 \%+$ овсяница красная $50 \%+$ люцерна гибридная $45 \%$. Во втором цикле стравливания в зависимости от видового состава трав и травосмесей достоверных различий по содержанию кормовых единиц нет (табл. 2). 
Влияние видового состава многолетних злаково-бобовых трав на содержание и сбор кормовых единиц, 2014-2016 гг.

\begin{tabular}{|c|c|c|c|c|c|c|}
\hline \multirow[b]{3}{*}{ Культура, смесь } & \multicolumn{6}{|c|}{ Цикл стравливания } \\
\hline & \multicolumn{2}{|c|}{ Первый } & \multicolumn{2}{|c|}{ Второй } & \multicolumn{2}{|c|}{ Третий } \\
\hline & $\begin{array}{l}\text { Содер- } \\
\text { жание, } \\
\text { корм. } \\
\text { ед./кг }\end{array}$ & $\begin{array}{c}\text { Сбор, } \\
\text { тыс./га }\end{array}$ & $\begin{array}{l}\text { Содержа- } \\
\text { ние, } \\
\text { корм. } \\
\text { ед./кг }\end{array}$ & $\begin{array}{c}\text { Сбор, } \\
\text { тыс./га }\end{array}$ & $\begin{array}{l}\text { Содер- } \\
\text { жание, } \\
\text { корм. } \\
\text { ед./кг }\end{array}$ & $\begin{array}{c}\text { Сбор, } \\
\text { тыс./га }\end{array}$ \\
\hline 1. Овсяница красная & 0,71 & 0,62 & 0,75 & 0,34 & 0,77 & 0,46 \\
\hline 2. Овсяница луговая & 0,83 & 0,71 & 0,82 & 0,42 & 0,80 & 041 \\
\hline 3. Тимофеевка луговая & 0,71 & 0,68 & 0,78 & 0,39 & 0,81 & 0,27 \\
\hline $\begin{array}{l}\text { 4. Кострец + овсяница луговая } \\
\text { +овсяница красная + } \\
\text { люцерна гибридная }\end{array}$ & 0,87 & 3,00 & 0,85 & 1,66 & 0,88 & 2,45 \\
\hline $\begin{array}{l}\text { 5. Кострец + тимофеевка + } \\
\text { овсяница красная + люцерна }\end{array}$ & 0,87 & 3,30 & 0,83 & 1,64 & 0,94 & 2,69 \\
\hline $\begin{array}{l}\text { 6. Кострец + тимофеевка + } \\
\text { овсяница красная + галега + } \\
\text { клевер красный }\end{array}$ & 0,79 & 1,91 & 0,85 & 1,15 & 0,89 & 1,74 \\
\hline $\mathrm{HCP}_{05}$ А смесь & 0,14 & 0,22 & 0,10 & 0,13 & 0,14 & 0,13 \\
\hline $\mathrm{HCP}_{05 \text { в год }}$ & 0,10 & 0,15 & 0,07 & 0,09 & 0,10 & 0,09 \\
\hline
\end{tabular}

В зависимости от года содержание кормовых единиц в сухом веществе кормов было различным и снижалось от 2014 к 2016 г. В первом цикле стравливания в 2014 г. оно составляло 1,05 корм. ед./кг; в 2015 г. - 0,79; в 2016 г. - 0,55 корм. ед./кг. Во втором цикле стравливания 0,93; 0,84 и 0,67 корм. ед./кг в 2014, 2015 и 2016 гг. соответственно. В третьем цикле стравливания - 0,89; 0,86 и 0,81 корм. ед./кг в 2014, 2015 и 2016 гг. соответственно.

Сбор кормовых единиц зависел от содержания кормовых единиц в сухом веществе пастбищных кормов, сбора сухого вещества, погодных условий лет исследования и цикла стравливания. Максимальный сбор кормовых единиц получен в первом цикле стравливания. Во всех циклах стравливания одновидовые посевы имели сбор кормовых единиц на уровне контро- ля, а исследуемые травосмеси многократно превосходили контроль. В первом цикле стравливания - в 3,1-5,3 раза; во втором цикле в 3,4-4,9; в третьем цикле стравливания в 3,8-5,8 раз (табл. 2). Основное влияние на содержание кормовых единиц в сухом веществе пастбищных трав оказывал фактор «культура, смесь» - $71 \%$.

Многофакторный дисперсионный анализ позволил установить, что основное влияние на сбор кормовых единиц многолетних пастбищных трав оказывали фракторы «культура, смесь» - 67,0 \% и взаимодействие факторов «культура, смесь $x$ цикл стравливания х год» - 12,3\%. По 5,8 \% влияния на сбор кормовых единиц приходилось на факторы «год» и «культура, смесь $\times$ цикл стравливания» (рис. 3). 


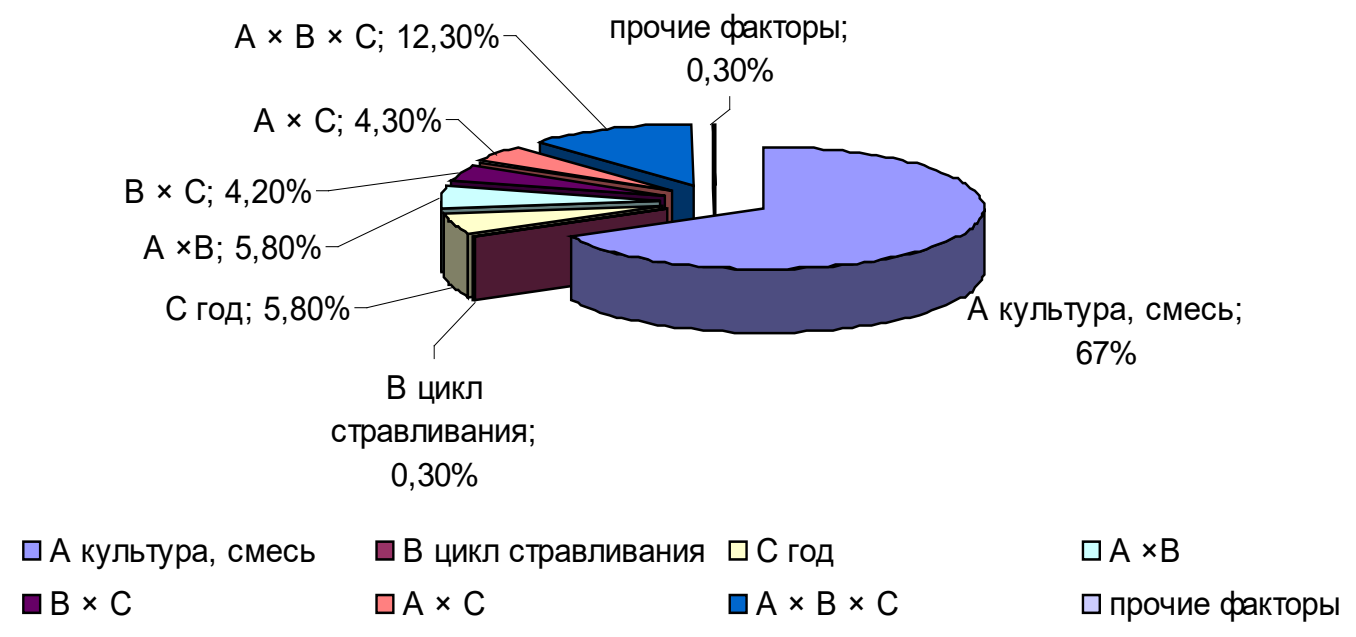

Puс. 3. Вклад факторов в изменчивость сбора кормовых единии долгосрочных пастбищ, \% $\left(F_{\text {факт }}>F_{05}\right)$

\section{Выводы}

1. Содержание кальция зависело от цикла стравливания, погодных условий лет исследований и вида трав; оно увеличивалось от первого цикла ставливания к третьему: от 0,48-1,79 \% в первом, 0,45-2,79 \% во втором до 0,85-3,04 \% в третьем цикле стравливания. Пастбищные травосмеси превосходили контроль овсяницу красную по содержанию кальция на 0,85-1,27; на 1,38-2,29; на 1,93-2,17 \% в первом, втором и третьем циклах стравливания соответственно.

2. Содержание фоссфора в сухом веществе пастбищных кормов зависело в большей степени от погодных условий лет исследования и цикла стравливания. Содержание фосфора снижалось от первого цикла стравливания к третьему: 0,86; 0,79 и 0,49 \% соответственно. В зависимости от видового состава различий по содержанию фоссфора в сухом веществе многолетних пастбищных трав и травосмесей не было.

3. Состав травосмесей и виды трав не оказывали существенного влияния на содержания магния в сухом веществе. Содержание магния зависело от цикла стравливания и погодных условий лет исследования; оно увеличивалось от первого цикла ставливания к третьему: от 0,26-0,71 \% в первом, 0,33-0,54 \% во втором до 0,47-0,67 \% в третьем цикле стравливания. Содержание магния в сухом веществе пасбищных кормов существенно различалось во втором и третьем циклах стравливания.
4. В зависимости от цикла стравливания достоверных различий по содержанию кормовых единиц нет. На содержание кормовых единиц оказывал влияние видовой состав трав и травосмесей в первом и третьем циклах стравливания. В первом цикле стравливания превосходили контроль травосмеси кострец + овсяница луговая + овсяница красная + люцерна и кострец + тимофеевка + овсяница красная + люцерна, имеющие содержание кормовых единиц 0,87 корм. ед./кг. В третьем цикле стравливания травосмесь кострец + тимофееевка + овсяница красная + люцерна содержала в 1 кг сухого вещества 0,94 корм. ед.

5. На сбор кормовых единиц многолетних пастбищных трав оказывали влияние фракторы «культура, смесь» - 67,0 \% и взаимодействие фракторов «культура, смесь $\times$ цикл стравливания х год» - 12,3\%. Сбор кормовых единиц зависел от содержания кормовых единиц в сухом веществе пастбищных кормов, выхода с единицы площади сухого вещества, погодных условий и цикла стравливания. В первом цикле стравливания сбор кормовых единиц пастбищных травосмесей превосходил контроль на 1,292,68 тыс./га; во втором - на 0,81-1,32; в третьем - на 1,28-2,23 тыс./га. Лучшей по сбору кормовых единиц была травосмесь кострец + тимофеевка + овсяница красная + люцерна, сбор у которой был 3,3 тыс./га, 1,64 тыс./га и 2,69 тыс./га в первом, втором и третьем циклах стравливания соответственно. 


\section{Литература}

1. Архив погоды в Сухобузимском районе. URL: rp5.ru.

2. Байкалова Л.П., Едимеичев Ю.Ф., Машанов А.И. Оценка урожайности культурных пастбищ в условиях Красноярской лесостепи // Вестн. КрасГАУ. - 2019. - № 8. - С. 52-59.

3. Байкалова Л.П., Едимеичев Ю.Ф., Колесников В.А. [и др.]. Пути интенсификации кормопроизводства в Красноярском крае // Вестн. КрасГАУ. - 2018. - № 5. - С. $102-$ 108.

4. Ваузен А. Продуктивность пастбищ. - М.: Колос, 1959. - 272 с.

5. Горянина Т.А. Урожайность и качество зеленой массы озимых культур в зависимости от сроков скашивания // КормопроизводстBo. - 2019. - № 6. - С. 23-27.

6. Доспехов Б.А. Методика полевого опыта. М.: Агропромиздат, 1985. - 351 с.

7. Максимюк Н.Н., Скопичев В.Г. Физиология животных: кормление. 2 изд. - М.: Урайт, 2017. - 265 c.

8. Методические указания по проведению полевых опытов с кормовыми культурами / ВНИИ кормов им. В.Р. Вильямса. - М., 1987. - 2-е изд. - 197 с.

9. Таранов М.Б., Сабиров А.Х. Биохимия кормов. - М.: Агропромиздат, 1987. - 224 с.

10. Сабитов Г.А. Ресурсосберегающие технологии создания высокопродуктивных пастбищ и сенокосов на суходолах в центральной Нечерноземноей зоне РФ: автореф. дис. ... д-ра с.-х. наук. - Великий Новгород, 2006. -40 C.

11. Савченко И.В. Состояние и перспективы развития луговодства в Российской Федерации // Роль культурных пастбищ в развитии молочного скотоводства Нечерноземной зоны России в современных условия: сб. мат-лов Междунар. науч.-практ. конф., посвящ. 50-летию АО «Михайловское» Ярославской области. - М., 2010. - С. 5-9.

12. Сорокин О.Д. Прикладная статистика на компьютере. - Новосибирск, 2009. - 162 с.

\section{Literatura}

1. Arhiv pogody $v$ Suhobuzimskom rajone. URL: rp5.ru

2. Bajkalova L.P., Edimeichev Yu.F., Mashanov A.I. Ocenka urozhajnosti kul'turnyh pastbishch $\mathrm{v}$ usloviyah Krasnoyarskoj lesostepi // Vestn. KrasGAU. - 2019. - № 8. S. 52-59.

3. Bajkalova L.P., Edimeichev Yu.F., Kolesnikov V.A. i dr. Puti intensifikacii kormoproizvodstva v Krasnoyarskom krae // Vestn. KrasGAU. - 2018. - № 5. - S. 102-108.

4. Vauzen A. Produktivnost' pastbishch. - M.: Kolos, 1959. - $272 \mathrm{~s}$.

5. Goryanina T.A. Urozhajnost' i kachestvo zelenoj massy ozimyh kul'tur v zavisimosti ot srokov skashivaniya // Kormoproizvodstvo. 2019. - № 6. - S. 23-27.

6. Dospekhov B.A. Metodika polevogo opyta. M.: Agropromizdat, 1985 - $351 \mathrm{~s}$.

7. Maksimyuk N.N., Skopichev V.G. Fiziologiya zhivotnyh: kormlenie. 2 izd. - M.: Urajt, 2017. - $265 \mathrm{~s}$.

8. Metodicheskie ukazaniya po provedeniyu polevyh opytov s kormovymi kul'turami. Izdanie vtoroe / VNII kormov im. V.R. Vil'yamsa, 1987. - M, 1987. - 2-e izd. $197 \mathrm{~s}$.

9. Taranov M.B., Sabirov A.H. Biohimiya kormov. - M.: Agropromizdat, 1987. - $224 \mathrm{~s}$.

10. Sabitov G.A. Resursosberegayushchie technologii sozdaniya vysokoproduktivnyh pastbishch i senokosov na suhodolah $v$ central'noj Nechernozemnoej zone RF: avtoref. dis. ... d-ra s.-h. nauk. - Velikij Novgorod, 2006. $-40 \mathrm{~s}$.

11. Savchenko I.V. Sostoyanie i perspektivy razvitiya lugovodstva v Rossijskoj Federacii // Rol' kul'turnyh pastbishch $v$ razvitii molochnogo skotovodstva Nechernozemnoj zony Rossii v sovremennyh usloviya: sb. matlov Mezhdunar. nauch.-prakt. konf., posvyashch. 50-letiyu AO «Mihajlovskoe» Yaroslavskoj oblasti. - M., 2010. - S. 5-9.

12. Sorokin O.D. Prikladnaya statistika na komp'yutere. - Novosibirsk, 2009. - $162 \mathrm{~s}$. 